\title{
RNA editing of 10 Didymium iridis mitochondrial genes and comparison with the homologous genes in Physarum polycephalum
}

\author{
STEPHEN J. TRAPHAGEN, ${ }^{1}$ MICHAEL J. DIMARCO, ${ }^{2}$ and MARGARET E. SILLIKER ${ }^{3}$ \\ ${ }^{1}$ The English High School, Boston Public Schools, Boston, Massachusetts 02130, USA \\ ${ }^{2}$ Medical College of Wisconsin, Milwaukee, Wisconsin 53226, USA \\ ${ }^{3}$ Department of Biological Sciences, DePaul University, Chicago, Illinois 60614, USA
}

\begin{abstract}
Regions of the Didymium iridis mitochondrial genome were identified with similarity to typical mitochondrial genes; however, these regions contained numerous stop codons. We used RT-PCR and DNA sequencing to determine whether, through RNA editing, these regions were transcribed into mRNAs that could encode functional proteins. Ten putative gene regions were examined: atp1, atp6, atp8, atp9, cox1, cox2, cytb, nad4L, nad6, and nad7. The cDNA sequences of each gene could encode a functional mitochondrial protein that was highly conserved compared with homologous genes. The type of editing events and editing sequence features were very similar to those observed in the homologous genes of Physarum polycephalum, though the actual editing locations showed a variable degree of conservation. Edited sites were compared with encoded sites in $D$. iridis and $P$. polycephalum for all 10 genes. Edited sequence for a portion of the cox 1 gene was available for six myxomycetes, which, when compared, showed a high degree of conservation at the protein level. Different types of editing events showed varying degrees of site conservation with $C$-to- $U$ base changes being the least conserved. Several aspects of single $C$ insertion editing events led to the preferential creation of hydrophobic amino acid codons that may help to minimize adverse effects on the resulting protein structure.
\end{abstract}

Keywords: base changes; editing conservation; insertional editing; Myxomycetes; Myxogastria; plasmodial slime molds

\section{INTRODUCTION}

RNA editing, the modification of an RNA molecule apart from what is encoded in the DNA template, was first described in the cox 2 mitochondrial gene of trypanosomes (Benne et al. 1986). Since that time RNA editing has been found to occur in diverse organisms by a variety of mechanisms (Gott 2003; Gray 2003). The most complex example of RNA editing has been observed in the plasmodial slime molds or Myxomycetes (Byrne and Gott 2004; Krishnan et al. 2007), a subgroup of the Mycetozoa (Baldauf et al. 2000; Fiore-Donno et al. 2005). Extensive C nucleotide insertions were reported in the atp 1 mitochondrial gene of the myxomycete Physarum polycephalum (Mahendran et al. 1991). Further studies revealed that $U$ insertions and mixed

Reprint requests to: Margaret E. Silliker, Department of Biological Sciences, DePaul University, 2325 North Clinton Avenue, Chicago, IL 60614, USA; e-mail: msillike@depaul.edu; fax: (773) 325-7596.

Article published online ahead of print. Article and publication date are at http://www.rnajournal.org/cgi/doi/10.1261/rna.1989310. dinucleotide insertion editing events also occur in the mitochondrial protein-coding genes and ribosomal RNAs of this organism (Miller et al. 1993; Mahendran et al. 1994). In addition to base insertions, $\mathrm{C}$-to- $\mathrm{U}$ changes occur in the coxl gene of several Myxomycetes (Gott et al. 1993; Horton and Landweber 2000). Recently, deletional editing has been found in P. polycephalum (Gott et al. 2005) and Stemonitis flavogenita (Krishnan et al. 2007).

A few studies have explored RNA editing across several species of plasmodial slime molds. Antes et al. (1998) compared $\mathrm{C}$ and $\mathrm{U}$ nucleotide insertions in the tRNAs of $P$. polycephalum and Didymium nigripes; the modifications conserved classical base pairing in the secondary structure of these RNAs, though the locations of insertion sites were not conserved between these species. A more extensive study of RNA editing in the SSU rRNA of seven myxomycetes also revealed a variety of types of editing events that conserved molecular secondary structure, but the specific modifications were only weakly conserved between species (Krishnan et al. 2007). A phylogenetic survey of RNA editing in the cox 1 gene of five Myxomycetes suggested 
a diversification of editing mechanisms within this group; at one extreme Clastoderma debaryanum only inserted $\mathrm{U}$ nucleotides, while at the other extreme, $P$. polycephalum and $D$. nigripes inserted $\mathrm{C}$ and $\mathrm{U}$ nucleotides, dinucleotides, and made C-to- $\mathrm{U}$ base changes (Horton and Landweber 2000).

Attempts to understand the mechanism of RNA editing at the biochemical level in $P$. polycephalum, reviewed by Gott and Rhee (2008), suggest that multiple pathways are involved in the different types of editing events, but that the insertion/deletion events are cotranscriptional. Recently, the $P$. polycephalum mitochondrial RNA polymerase has been cloned (Miller et al. 2006), and it has been found to add non-DNA-templated nucleotides to the $3^{\prime}$ end of RNAs (Miller and Miller 2008). Using chimeric templates and in vitro mitochondrial transcription elongation complexes Rhee et al. (2009) demonstrated the importance of 9 base pairs (bp) to either side of $\mathrm{C}$ insertion sites in directing this type of editing event.

Analysis of the features of editing sites, combined with statistical analysis of the amino acid variation in specific proteins, has lead to an algorithm that predicts insertional editing events (Bundschuh 2004). This algorithm, Predictor of Insertional Editing (PIE), identified four genes in the $P$. polycephalum mitochondrial genome, which were undetected by typical similarity searches (Gott et al. 2005). Additional bioinformatics approaches have been developed that have greatly increased the number of predicted genes in P. polycephalum (Beargie et al. 2008).

Here, we present the RNA editing patterns for 10 protein-coding genes of the myxomycete Didymium iridis. $P$. polycephalum and $D$. iridis belong to the same order of Myxomycetes (Fiore-Donno et al. 2005). These organisms have been estimated to have diverged 400-500 million years ago, based on nuclear LSU sequence data (Johansen et al. 1992). Over $48 \mathrm{~kb}$ of the $D$. iridis mitochondrial genome has been sequenced. Though the genome contains open readings frames, these regions do not correspond to typical mitochondrial genes. Interestingly, the genomic regions that do show similarity to typical mitochondrial genes are interrupted by stop codons (ME Silliker, unpubl.). RT-PCR and DNA sequencing were used to verify that the putative gene regions code for functional mRNAs through RNA editing. We characterized the types of editing events in $D$. iridis and compared the sequence features of editing sites to determine resemblances with the patterns seen in $P$. polycephalum. Gene-by-gene comparisons allowed us to determine the degree of conservation of actual editing events. We also analyzed the amino acids codons created by editing events and noted a bias toward hydrophobic residues; possible reasons for this bias are offered in the discussion.

\section{RESULTS}

\section{The distribution pattern of different types of editing events in $D$. iridis genes were similar to $P$. polycephalum genes}

The 10 genes analyzed consist of 8060 bp of genomic DNA and 8394 bp of edited sequence; the difference was due to $303 \mathrm{C}$ insertions, $9 \mathrm{U}$ insertions, and 22 bases from 11 dinucleotide insertions. In addition, C-to- $\mathrm{U}$ base changes occurred in the $\operatorname{cox} 1$ and $\operatorname{cox} 2$ genes. The number and distribution of different types of editing events are presented in Table 1. C insertions occurred in all 10 genes, and $\mathrm{U}$ insertions occurred in four genes, while dinucleotide insertions and base change events were rare. Editing was necessary to abolish numerous stop codons in all 10 genes.

The genes are grouped in Table 1 according to the types of editing events observed. Five genes-atp1, atp6, atp8, atp9, and nad4L-only have $\mathrm{C}$ insertions, while nad6 has both $\mathrm{C}$ and $\mathrm{U}$ insertions. Dinucleotide insertions occurred

TABLE 1. Summary of the types of editing events in ten $D$. iridis protein coding genes, the loss of stop codons, and change in size

\begin{tabular}{|c|c|c|c|c|c|c|}
\hline \multirow[b]{2}{*}{ Gene } & \multicolumn{4}{|c|}{ Type of editing event } & \multirow[b]{2}{*}{$\begin{array}{l}\text { Stop codons } \\
\text { lost by editing }\end{array}$} & \multirow{2}{*}{$\begin{array}{c}\text { Gene size } \\
\text { before/after editing } \\
\text { (in base pairs) }\end{array}$} \\
\hline & $\begin{array}{c}\mathrm{C} \\
\text { insertion }\end{array}$ & $\begin{array}{c}U \\
\text { insertion }\end{array}$ & $\begin{array}{l}\text { Dinucleotide } \\
\text { insertion }\end{array}$ & $\begin{array}{l}\text { C-to-U } \\
\text { change }\end{array}$ & & \\
\hline atp1 & 64 & & & & 28 & $1487 / 1551$ \\
\hline atp6 & 32 & $0^{\mathrm{a}}$ & & & 18 & $706 / 738$ \\
\hline atp8 & 8 & & & & 5 & $223 / 231$ \\
\hline atp9 & 7 & & & & 5 & $215 / 222$ \\
\hline nad4L & 13 & & & & 8 & $275 / 288$ \\
\hline nad6 & 18 & 1 & & & 8 & $485 / 504$ \\
\hline cytb & 28 & 4 & 3 & & 28 & $1120 / 1158$ \\
\hline nad7 & 36 & 2 & 5 & & 29 & $1155 / 1203$ \\
\hline $\cos 2$ & 33 & & & $1^{b}$ & 20 & $681 / 714$ \\
\hline $\operatorname{cox} 1$ & 64 & 2 & 3 & 2 & 27 & $1713 / 1785$ \\
\hline Bases added & 303 & 9 & 22 & & & $8060 / 8394$ \\
\hline
\end{tabular}


along with $\mathrm{C}$ and $\mathrm{U}$ insertions in cytb and nad7. The cox 1 gene has two $\mathrm{C}$-to- $\mathrm{U}$ base changes as well as $\mathrm{C}, \mathrm{U}$, and dinucleotide insertions. This distribution of different types of editing events is identical to the types of editing events observed in the homologous genes in $P$. polycephalum, reviewed by Gott and Rhee (2008) (Supplemental Table 1; Supplemental Data Alignments). The only difference in the types of editing events occurred between the cox 2 and atp6 genes of $D$. iridis and $P$. polycephalum. In the D. iridis cox 2 gene, one C-to- $\mathrm{U}$ base change occurred along with $\mathrm{C}$ insertions; only $\mathrm{C}$ insertions occur in the cox 2 gene of $P$. polycephalum (Gott et al. 2005). The atp6 gene of $P$. polycephalum has a U insertion (Beargie et al. 2008), but no $\mathrm{U}$ insertions occurred in the $D$. iridis atp6 gene.

Another interesting difference was the use of a UAG termination codon in the $D$. iridis atp 9 gene. The other nine $D$. iridis genes and the homologous $P$. polycephalum genes all terminate with UAA. It should be noted that a UAA codon appears in frame in the second codon after the UAG codon in the D.iridis atp9 gene. This was the sole use of a UAG codon in all 10 genes of both organisms.

\section{Single C insertions predominated and were partially shared}

Single C insertions comprised the majority of insertional events (90\%), which is identical to that observed in $P$. polycephalum (Miller et al. 1993; Gott and Rhee 2008). The average interval between single $\mathrm{C}$ insertion events was $27.2 \pm 5.9 \mathrm{bp}$ for the 10 genes (Supplemental Table 2). This is comparable to $\mathrm{C}$ insertions occurring on an average of every 25 bp in P. polycephalum mRNA (Miller et al. 1993).
The exact location of some $\mathrm{C}$ insertions was ambiguous if the $\mathrm{C}$ was inserted next to another $\mathrm{C}$. However, assuming the smallest possible interval, $\mathrm{C}$ insertions were never $<9 \mathrm{bp}$ apart. This is consistent with the experimental finding of Rhee et al. (2009), which determined that information in the 9 bp upstream of and downstream from an insertion site are necessary for proper insertional editing.

Given the similarity in $\mathrm{C}$ insertion pattern, we compared the actual single $\mathrm{C}$ insertion sites between $D$. iridis and $P$. polycephalum (Table 2). Ambiguous $\mathrm{C}$ insertions that could be aligned between the two organisms were counted as shared insertion sites, though it is possible that the sites could differ by $1-2$ bp in strings of $2-3$ consecutive C's. The percent of shared $\mathrm{C}$ insertions was calculated with respect to $D$. iridis, that is, the number of shared sites divided by the total number of single $\mathrm{C}$ insertions in $D$. iridis. Some of the single $\mathrm{C}$ insertions unique to one organism aligned with encoded $\mathrm{C}$ nucleotides in the other organism; this conserves the mRNA sequence between both organisms (these are noted in parentheses as a subset of the unique insertions for $D$. iridis and $P$. polycephalum). The percent of unique $\mathrm{C}$ insertions that matched a $\mathrm{C}$ nucleotide in the other organism was $29.3 \%$ (based on the combined data for both organisms). The average percent of shared $\mathrm{C}$ insertions for all 10 genes was $76.8 \%$; the range was from a low of $26.6 \%$ in the 1551-bp atp 1 gene to a high of $100 \%$ in the 288 -bp nad4L gene. However, gene length was not related to the degree of shared $\mathrm{C}$ insertions. The inverse relationship exists between size and degree of conservation between the relatively short 222-bp atp9 gene that had only $42.9 \%$ shared $\mathrm{C}$ insertions, while the longest gene analyzed, the 1785-bp coxl gene, had $84.4 \%$ shared C insertions.

TABLE 2. Comparison of single $C$ insertions in D. iridis and $P$. polycephalum

\begin{tabular}{|c|c|c|c|c|c|c|c|c|c|c|c|}
\hline \multirow[b]{2}{*}{ Organism } & \multirow[b]{2}{*}{ Parameter } & \multicolumn{10}{|c|}{ Gene $^{a}$} \\
\hline & & atp1 & atp6 & atp8 & atp9 & $\operatorname{cox} 1$ & $\operatorname{cox} 2$ & cytb & nad4L & nad6 & nad7 \\
\hline \multirow[t]{5}{*}{ D. iridis } & Size $(b p)^{b}$ & 1551 & 738 & 231 & 222 & 1785 & 714 & 1158 & 288 & 504 & 1203 \\
\hline & Total $^{\mathrm{C}}$ & 64 & 32 & 8 & 7 & 64 & 33 & 28 & 13 & 18 & 36 \\
\hline & Unique $^{\mathrm{d}, \mathrm{e}}$ & $47(14)$ & $3(1)$ & $2(1)$ & $4(1)$ & $10(3)$ & 1 & 2 & 0 & 5 & $5(1)$ \\
\hline & Shared & 17 & 29 & 6 & 3 & 54 & 32 & 26 & 13 & 13 & 31 \\
\hline & Unique $^{\mathrm{d}, \mathrm{e}}$ & $37(14)$ & $3(1)$ & 3 & $6(1)$ & 5 & 1 & $5(3)$ & 0 & $5(2)$ & $6(2)$ \\
\hline \multirow[t]{3}{*}{ P. polycephalum } & Total $^{\mathrm{c}}$ & 54 & 32 & 9 & 9 & 59 & 33 & 31 & 13 & 18 & 37 \\
\hline & Size $(b p)^{b}$ & 1590 & 741 & 231 & 233 & 1785 & 717 & 1179 & 288 & 498 & 1206 \\
\hline & Percent ${ }^{f}$ & 26.6 & 90.6 & 75.0 & 42.9 & 84.4 & 97.0 & 92.9 & 100 & 72.2 & 86.1 \\
\hline
\end{tabular}

${ }^{\mathrm{a} A c c e s s i o n}$ numbers for $P$. polycephalum sequences: (Ppatp1-D) AB027295.1, (Ppatp1-R) M31718, (Ppatp6-D) AB027295.1, (Ppatp6-D) AB027295.1, (Ppatp6-R) FJ154098.1, (Ppatp8-D) AB027295.1, (Ppatp8-R) DQ092488.1, (Ppatp9-D) AB027295.1, (Ppatp9-R) S67221, (Ppcox1-D) L14779.2, (Ppcox1-R) L14769.1, (Ppcox2-D) AB027295.1, (Ppcox2-R) DQ092489, (Ppcytb-D) AB027295.1, (Ppcytb-R) AF079799.1, (Ppnad4L-D) AB027295.1， (Ppnad4L-R) DQ092491， (Ppnad6-D) AB027295.1， (Ppnad6-R) DQ092492, (Ppnad7-D) AB027295.1, (Ppnad7-R) (AB027295.1).

${ }^{\mathrm{b}} \mathrm{Size}$ in base pairs of edited ORF.

${ }^{\mathrm{C}}$ Total number of single $\mathrm{C}$ insertions.

${ }^{\mathrm{d}}$ Single $\mathrm{C}$ insertions not shared between the two organisms.

eNumbers in parentheses represent nonshared $C$ insertions that match encoded bases in the other organism.

${ }^{f}$ Percent of $D$. iridis $C$ insertions shared with $P$. polycephalum. 


\section{C insertions are more frequent in the third codon position}

Of the 211 single $\mathrm{C}$ insertions that could be assigned to a codon position in the $10 \mathrm{D}$. iridis genes studied, the majority were in the third codon position, 125 (59\%), while 66 (31\%) were in the first codon position, and 20 (9\%) were in the second codon position (Supplemental Table 3). This preference order, third $>$ first $>$ second, was consistent for all of the genes except atp8, where two C insertions could be assigned to codon positions 2 and 3 and one $\mathrm{C}$ insertion to codon position 1 (it should be noted that three additional $\mathrm{C}$ insertions in this gene could not be definitively assigned to a codon position). The same pattern of codon position preference was found in $11 \mathrm{P}$. polycephalum genes: $64 \%$ in the third position, $26 \%$ in the first codon position, and $11 \%$ in the second codon position (Gott et al. 2005).

\section{C insertions preferentially follow purine- $U$ sequences}

The nucleotides one and two bases upstream of unambiguous single $\mathrm{C}$ insertion sites, in the $10 \mathrm{D}$. iridis genes examined, are summarized in Table 3. Sixteen dinucleotide combinations are possible, but $\mathrm{C}$ insertions follow $\mathrm{AU}$ and GU dinucleotides 65\% percent of the time (104 AU and 34 GU out of 211 total). The presence of these dinucleotide combinations is greater than what would be expected by multiplying the individual nucleotide frequencies at each position (the expected numbers based on individual nucleotide frequencies are in parentheses). A similar C insertion bias was noted in P. polycephalum in the first gene analyzed (Mahendran et al. 1991). In a combined data set of $11 \mathrm{P}$. polycephalum genes, $69 \%$ of unambiguous C insertions followed purine- $U$ dinucleotides (Gott et al. 2005). The observation was also made in $P$. polycephalum that repeated dinucleotides, for example, AA or UU, were under-represented upstream of $\mathrm{C}$ insertions (Gott et al. 2005). Our data were consistent with that pattern.

TABLE 3. Bases upstream of single $C$ insertions in ten D. iridis genes

\begin{tabular}{lcccc}
\hline & \multicolumn{5}{c}{-1} \\
\cline { 2 - 5 }-2 & $\mathrm{~A}$ & $\mathrm{U}$ & $\mathrm{G}$ & Total (\% total) \\
\hline $\mathrm{A}$ & $13(21)^{\mathrm{a}}$ & $104(99)$ & $11(10)$ & $128(60.7 \%)$ \\
$\mathrm{U}$ & $14(5)$ & $18(26)$ & $2(3)$ & $34(16.1 \%)$ \\
$\mathrm{G}$ & $5(6)$ & $34(31)$ & $1(3)$ & $41(18.9 \%)$ \\
$\mathrm{C}$ & $1(1)$ & $6(7)$ & $2(1)$ & $8(4.3 \%)$ \\
Total (\% total) & $33(15.6 \%)$ & $162(76.8 \%)$ & $16(7.6 \%)$ & $100 \%$ \\
\hline
\end{tabular}

${ }^{\mathrm{a}}$ Thirteen AA dinucleotides were observed upstream of unambiguous single $C$ insertions, representing the -2 and -1 positions. The number in parentheses is the expected number of upstream AA dinucleotides based on multiplying the total frequency of A's in the -2 position by the frequency of A's in the -1 position by the total number of single $\mathrm{C}$ insertions analyzed.
Though the absolute number of $\mathrm{C}$ insertions following a UA dinucleotide was small, the occurrence is much greater than expected by chance (14 occurred, five were expected). This insertion bias was also present in the $11 P$. polycephalum genes analyzed (Gott et al. 2005). A third codon position $\mathrm{C}$ insertion following UA would create a tyrosine codon; a second codon position $\mathrm{C}$ insertion following UA would create a threonine codon. A first position $\mathrm{C}$ insertion following UA could create five different types of amino acid codons with hydrophobic, hydrophilic, or positively charged chemical properties.

It should be noted that the number of $\mathrm{C}$ nucleotides in the -1 position are most likely underestimated because two consecutive $\mathrm{C}$ nucleotides introduces ambiguity that removes these events from consideration. When a CC dinucleotide pair could be assigned to a single codon, the upstream nucleotide was a purine $81.2 \%$ of the time $(50 \%$ would be expected due to chance). While it cannot be assumed that the second $\mathrm{C}$ is the inserted nucleotide, these data were consistent with a possible purine-C editing target sequence (as well as purine-U; Supplemental Table 4).

\section{Codons for hydrophobic amino acids are preferentially created by $\mathrm{C}$ insertions}

In Table 4 the codon usage for the $10 \mathrm{D}$. iridis genes is compared with the codons created by editing. Twenty of the 303 single $C$ insertions (or 6.6\%) could not be unambiguously assigned to a codon; these are included in the codon usage numbers but not in the number of codons created. (A greater number of $\mathrm{C}$ insertions were ambiguous with respect to codon position, but most could be assigned to a codon.)

The most common created codons, AUC and GUC, reflect the purine-U-insertion bias (Table 4) and third position codon bias (Supplemental Table 3). If the codons created are categorized by their physico-chemical properties, according to Biro et al. (2003), then a differential pattern of editing emerges (Table 5). Hydrophobic amino acids comprise $53.2 \%$ of the amino acid residues, but $67.5 \%$ of the amino acids encoded by edited codons. Codons for charged amino acids are underrepresented in editing events relative to total codons for charged amino acid. Codons for positively and negatively charged amino acids make up $9.6 \%$ and $7.0 \%$ of the total codons, but only $4.6 \%$ and $0.7 \%$, respectively, of the codons created by editing events. A $\chi^{2}$ test was done based on the null hypothesis that codons are edited randomly with respect to amino acid properties and should therefore be present in roughly the same proportion as overall codon usage. This hypothesis was rejected $(P<0.001)$.

Another way to evaluate codon creation bias is by considering the proportion of codons with a central pyrimidine compared with a central purine (Table 4). Though 61.4\% of the codons used have a central pyrimidine $(41.4 \% \mathrm{U}$ and $20.0 \% \mathrm{C}$ ), $84.1 \%$ of the created codons have a central 
TABLE 4. Codon usage compared to codon creation in $10 \mathrm{D}$. iridis genes

\begin{tabular}{|c|c|c|c|c|c|c|c|c|c|c|c|c|c|c|c|c|}
\hline & \multicolumn{16}{|c|}{ Second base } \\
\hline & $\begin{array}{l}\text { Codon } \\
\text { usage }\end{array}$ & $\begin{array}{l}\text { Codons } \\
\text { created }\end{array}$ & & & $\begin{array}{l}\text { Codon } \\
\text { usage }\end{array}$ & $\begin{array}{l}\text { Codons } \\
\text { created }\end{array}$ & & & $\begin{array}{l}\text { Codon } \\
\text { usage }\end{array}$ & $\begin{array}{l}\text { Codons } \\
\text { created }\end{array}$ & & & $\begin{array}{l}\text { Codon } \\
\text { usage }\end{array}$ & $\begin{array}{l}\text { Codons } \\
\text { created }\end{array}$ & & \\
\hline \multirow{5}{*}{$\mathrm{T}$} & \multicolumn{4}{|c|}{$\mathrm{T}$} & \multicolumn{4}{|c|}{ C } & \multicolumn{4}{|c|}{ A } & \multicolumn{4}{|c|}{ G } \\
\hline & 187 & 0 & TTT & Phe & 85 & 7 & TCT & Ser & 124 & 1 & TAT & Tyr & 21 & 0 & TGT & Cys \\
\hline & 51 & 10 & TTC & Phe & 14 & 6 & TCC & Ser & 15 & 3 & TAC & Tyr & 1 & 0 & TGC & Cys \\
\hline & 274 & 0 & TTA & Leu & 23 & 6 & TCA & Ser & 9 & 0 & TAA & Stop & 0 & 0 & TGA & Stop \\
\hline & 13 & 0 & TTG & Leu & 1 & 0 & TCG & Ser & 1 & 0 & TAG & Stop & 30 & 0 & TGG & Trp \\
\hline \multirow{4}{*}{ C } & 80 & 23 & CTT & Leu & 61 & 14 & CCT & Pro & 58 & 4 & САT & His & 57 & 5 & CGT & Arg \\
\hline & 13 & 4 & СТС & Leu & 1 & 1 & $\mathrm{CCC}$ & Pro & 9 & 1 & CAC & His & 10 & 1 & CGC & Arg \\
\hline & 16 & 11 & CTA & Leu & 46 & 9 & CCA & Pro & 68 & 11 & CAA & GIn & 10 & 2 & CGA & Arg \\
\hline & 2 & 2 & CTG & Leu & 2 & 0 & CCG & Pro & 1 & 0 & CAG & Gln & 0 & 0 & CGG & Arg \\
\hline \multirow{4}{*}{ A } & 119 & 0 & ATT & Ile & 72 & 3 & ACT & Thr & 89 & 0 & AAT & Asn & 43 & 0 & AGT & Ser \\
\hline & 81 & 64 & ATC & Ile & 28 & 25 & $\mathrm{ACC}$ & Thr & 33 & 7 & AAC & Asn & 13 & 7 & AGC & Ser \\
\hline & 78 & 0 & ATA & Ile & 33 & 0 & ACA & Thr & 93 & 0 & AAA & Lys & 22 & 0 & AGA & Arg \\
\hline & 63 & 0 & ATG & Met/start & 0 & 0 & ACG & Thr & 8 & 0 & AAG & Lys & 0 & 0 & AGG & Arg \\
\hline \multirow{4}{*}{ G } & 67 & 0 & GTT & Val & 125 & 4 & GCT & Ala & 88 & 0 & GAT & Asp & 123 & 0 & GGT & Gly \\
\hline & 47 & 29 & GTC & Val & 35 & 20 & GCC & Ala & 9 & 2 & GAC & Asp & 10 & 1 & GGC & Gly \\
\hline & 50 & 0 & GTA & Val & 29 & 0 & GCA & Ala & 97 & 0 & GAA & Glu & 35 & 0 & GGA & Gly \\
\hline & 12 & 0 & GTG & Val & 2 & 0 & GCG & Ala & 2 & 0 & GAG & Glu & 9 & 0 & GGG & Gly \\
\hline & Total & 1153 & 143 & & & 557 & 95 & & & 704 & 29 & & & 384 & 16 & \\
\hline & $\%$ & $41.4 \%$ & $50.5 \%$ & & & $20.0 \%$ & $33.6 \%$ & & & $25.3 \%$ & $10.2 \%$ & & & $13.8 \%$ & $5.7 \%$ & \\
\hline & & \multicolumn{3}{|c|}{ Hydrophobic } & \multicolumn{4}{|c|}{ Hydrophilic } & \multicolumn{4}{|c|}{ Positively charged } & \multicolumn{4}{|c|}{ Negatively charged } \\
\hline
\end{tabular}

pyrimidine $(50.5 \% \mathrm{U}$ and $33.6 \% \mathrm{C})$. Conversely, $39.1 \%$ of the codons used have central purine $(25.3 \% \mathrm{~A}$ and $13.8 \% \mathrm{G})$, but only $15.9 \%$ of the created codons have a central purine $(10.2 \% \mathrm{~A}$ and $5.7 \% \mathrm{G})$. The codon usage table clearly illustrates that by avoiding codons with second position purines, all charged amino acids (and stop codons) are avoided and hydrophobic amino acids are favored.

\section{$U$ and dinucleotide insertion events were more conserved}

$\mathrm{U}$ insertion events were either shared or, when not shared, conserved the mRNA sequence between the two organisms (Table 6). All of the $U$ insertions had greater than $9 \mathrm{bp}$ to either side of their insertion site. All dinucleotide insertion events were conserved between $D$. iridis and $P$. polycephalum. All of the dinucleotide insertions in D. iridis were separated from other editing events by greater than $9 \mathrm{bp}$ to either side of their insertion site.

\section{C-to-U base change events were not conserved}

Two C-to-U base changes were present in the cox 1 gene of D. iridis, while four C-to-U base changes occur in the cox1 gene of P. polycephalum (Gott et al. 1993). None of the $\mathrm{C}$-to-U events in the cox 1 gene were shared between the

TABLE 5. Types of codons created versus types of codons used

\begin{tabular}{|c|c|c|c|c|c|}
\hline & & \multicolumn{2}{|c|}{ Codons created } & \multicolumn{2}{|c|}{ Total codon usage } \\
\hline \multirow{5}{*}{ 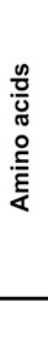 } & Hydrophobic & 191 & $67.5 \%$ & 1484 & $53.2 \%$ \\
\hline & Hydrophilic & 77 & $27.2 \%$ & 841 & $30.2 \%$ \\
\hline & Positively charged & 13 & $4.6 \%$ & 267 & $9.6 \%$ \\
\hline & Negatively charged & 2 & $0.7 \%$ & 196 & $7.0 \%$ \\
\hline & Totals & 283 & & 2788 & \\
\hline
\end{tabular}


TABLE 6. Summary of comparison of editing events (other than single $C$ insertions) in five mitochondrial protein-coding genes of $D$. iridis and P. polycephalum

\begin{tabular}{|c|c|c|c|c|c|c|c|c|}
\hline \multirow[b]{3}{*}{ Gene } & \multicolumn{7}{|c|}{ Type of editing event } & \multirow{3}{*}{$\begin{array}{l}\text { C-to-U } \\
\text { changes } \\
\text { (unique) }\end{array}$} \\
\hline & \multicolumn{2}{|c|}{$U$ insertion } & \multicolumn{5}{|c|}{ Dinucleotide insertion $^{a}$} & \\
\hline & Shared & Unique & $\mathrm{CU}$ & UU & $\mathrm{AU}$ & GU & GC & \\
\hline nad6 & 1 & & & & & & & \\
\hline cytb & 3 & $1(1) b$ & 2 & & & & 1 & \\
\hline nad7 & 2 & & 2 & 2 & & 1 & & \\
\hline $\operatorname{cox} 1$ & 1 & 1(1) & 1 & & 1 & 1 & & $2(2)$ \\
\hline $\operatorname{cox} 2$ & & & & & & & & $1(1)$ \\
\hline
\end{tabular}

${ }^{\mathrm{a}} \mathrm{All}$ of the dinucleotide insertions were conserved.

${ }^{b}$ Numbers in parentheses indicate whether the sequence is conserved between both organisms due to an editing event in one organism, this unique $U$ insertion event in $D$. iridis matchs the genomic sequence in $P$. polycephalum. All of the unique editing events conserve the sequence of the encoded mRNAs at the homologous locations; these are shaded in gray. (See Table 2 for the accession numbers for the edited $P$. polycephalum sequences.)

two organisms, but in all cases, a base change in the mRNA of one organism matched the encoded sequence of the other organism at the homologous site. The one C-to- $\mathrm{U}$ base change in the cox 2 gene of $D$. iridis also results in conserving the sequence with that encoded in $P$. polycephalum. By comparison, no C-to-U base changes were observed in the cox2 gene of $P$. polycephalum (Gott et al. 2005). The three C-to-U base changes in D. iridis (as well as the four in P. polycephalum) occurred in the first or second codon positions.

\section{The cox1 protein sequence of six Myxomycetes is conserved}

Incomplete edited mRNA sequences are available for the coxl gene of four myxomycetes (Horton and Landweber 2000) in addition to the complete sequences for $D$. iridis (this study) and P. polycephalum (Gott et al. 1993). The result of editing events (other than single $\mathrm{C}$ insertions) was to produce a highly conserved protein sequence among the six species. This occurred either by shared editing events or by conserved mRNA sequences (between edited and encoded sequences) or by encoding amino acids with similar properties. Collectively, there were 10 distinct $U$ insertion sites, five distinct dinucleotide insertion sites, and 12 distinct C-to-U base changes for the available gene sequences (some genes were only partially characterized). The number of $\mathrm{C}$ insertions varied widely and will not be considered here. The two $\mathrm{U}$ insertions in $D$. iridis were either shared by the other five organisms, or the mRNA sequence was conserved at these locations, with one exception. In Arcyria cinerea, this site is not edited and encodes a hydrophobic alanine residue, while a hydrophilic glycine residue is encoded in the five other species, including $D$. iridis. In all other cases, the chemical properties of the amino acids encoded at these variably edited sites were conserved. The dinucleotide editing sites were the most conserved at the sequence level. Of the $12 \mathrm{C}$-to- $\mathrm{U}$ bases changes, only $D$. iridis and $D$. nigripes share a single site, all of the rest are unique to each species but result in conserved protein sequences.

\section{DISCUSSION}

\section{Editing profiles are gene specific and conserved}

The complexity of RNA editing in the plasmodial slime molds is staggering (Horton and Landweber 2000; Byrne and Gott 2004; Krishnan et al. 2007). However, not all genes demonstrate this potential complexity. In $D$. iridis, as well as in $P$. polycephalum, the editing profile of a gene can vary from only single $\mathrm{C}$ insertions to $\mathrm{C}, \mathrm{U}$, and dinucleotide insertions along with $\mathrm{C}$ to $\mathrm{U}$ changes. We did not find evidence of deletional editing in $D$. iridis; however, we did not study the genes homologous to $P$. polycephalum and $S$. flavogenita, where this type of editing was observed (Gott et al. 2005; Krishnan et al. 2007). Given the diverse types of possible editing events, it is of interest to note that when the editing profiles of the $10 \mathrm{D}$. iridis genes described in this study were compared with the homologous genes in $P$. polycephalum, the editing profiles were very similar (Tables 1, 2; Supplemental Table 1). The only difference was the presence of a C-to- $U$ base change in the D. iridis cox 2 gene and a $\mathrm{U}$ insertion in the $P$. polycephalum atp6 gene, while these types of editing events were absent in the other organism. In all other cases, the types of editing events present were the same in homologous genes. These similar profiles most likely reflect the genes' shared evolutionary history, but it is curious as to why some genes rely on several editing mechanisms, while other genes use a more limited repertoire. This also raises the caution that editing data from a limited number of any myxomycetes' genes may not reveal the complete range of editing capabilities in that organism.

The single use of a UAG codon in the atp9 gene does not resolve the question of whether this is a stop codon or a rarely used amino acid codon. In a study of four dictyostelids, one of the three subgroups of the Mycetozoa, a similar stop codon usage profile was observed (Heidel and Glockner 2008). UAA was the preferred stop codon and UAG was infrequently used. Dictyostelium fasciculatum does not use the UGA codon, which is rarely used by the other three dictyostelid species studied. The nad9 gene of $P$. polycephalum may be terminated with a UGA codon or with a UAA codon that immediately follows (Beargie et al. 2008). In our study the UGA codon was never used and the UAG codon was used only once, followed closely by a UAA codon. 


\section{Single $C$ insertions preferentially insert in the third codon position following purine-pyrimdine dinucleotides to create mostly hydrophobic amino acid codons}

Single C insertions were the most common type of editing event in the $D$. iridis genes examined. The degree of conservation of $\mathrm{C}$ insertion editing sites between homologous $D$. iridis and $P$. polycephalum genes varied widely (26.6\%-100\%, average $76.8 \%)$ despite the predominance of that type of editing event in both organisms and the similar spacing intervals. When unique $\mathrm{C}$ insertion editing sites in one organism were compared with encoded nucleotides in the equivalent position in the other organism, the encoded site contained a C nucleotide $29 \%$ of the time. In this genome, $\mathrm{C}$ nucleotides make up about $12 \%$ of the bases (ME Silliker, unpubl.), so while $\mathrm{C}$ nucleotides are enriched at these positions, it does not appear that the identity of the nucleotide is critical in terms of specifying a particular amino acid. Rather, the $\mathrm{C}$ insertions most likely serve as placeholders in mRNA, their role being to reverse the effect of deletions in the genome by restoring the reading frame.

The above interpretation is consistent with a model for the evolution of RNA editing where a pre-existing biochemical ability to alter RNA becomes co-opted to reverse mutations; eventually, the process becomes fixed through coevolution (Covello and Gray 1993). Scenarios specific to the evolution of insertional RNA editing in the myxomycetes have been developed (Krishnan et al. 2007; Speijer 2008). In envisioning the evolutionary processes and constraints that shaped RNA editing, one must think on three levels-in terms of DNA, RNA, and protein considerations. At the DNA level, what types of mutations might occur to drive editing? And what kinds of mutations are less likely to be restored by classical reversion? Krishnan et al. (2007) noted that reversion of deletion events are rare. At the RNA level, what types of modifications are possible, how are the target sites recognized, and the changes specified? For stable RNAs, what is the effect of changes on structure? At the protein level, what are the consequences and constraints? It may be difficult to determine whether the observed patterns are a consequence of natural selection or an intrinsic feature of the editing mechanism, or the relative contributions of each.

The preference for $\mathrm{C}$ insertions in the third codon position of mRNAs clearly seems to be due to a constraint at the protein level. Insertions at this position are least likely to affect protein structure. In fact, a model of RNA editing based on selection at the protein level closely predicts the position bias seen in $P$. polycephalum, and in $D$. iridis as well (Liu and Bundschuh 2005).

A phylogenetic analysis of RNA editing in the coxl gene of five myxomycetes led to the assertion that $\mathrm{U}$ insertions are ancestral to $\mathrm{C}$ insertions in this group (Horton and
Landweber 2000). Genetic drift has been proposed as the reason for this change (Speijer 2008). It is interesting to note that a $\mathrm{C}$ nucleotide insertion is the only nucleotide that guarantees that the resulting codon will not be a stop codon. Therefore, a preference for $\mathrm{C}$ insertions could confer a selective advantage at the protein level in an AT-rich mitochondrial genome. Additionally, an increase in $\mathrm{C}$ nucleotides in stable RNAs might increase the number of G-C base pairs, adding to structural stability.

Though a signature insertion signal has not been identified, the bias toward $\mathrm{C}$ insertions that follow an upstream purine-pyrimidine was recognized in the first edited myxomycete gene (Mahendran et al. 1991), and this pattern has held in P. polycephalum (Gott et al. 2005; Krishnan et al. 2007) and occurs in D. iridis (this study). Speijer (2008) proposed that this bias may be the result of a deletion-prone DNA polymerase that preferentially causes deletions following a purine-pyrimidine DNA sequence, essentially creating the editing site. Though purine-U upstream bases are the most common, we argue that purinepyrimidine dinucleotides may be the relevant target. Purine-C insertions are undercounted, because a purine$\mathrm{C}-\mathrm{C}$ insertion creates an ambiguity. If the purine-pyrimidine bias is coupled with the preference for third position $\mathrm{C}$ insertions, then it may be the central pyrimidine that is most relevant in determining the properties of the encoded amino acid. While the third codon position is largely silent, the second codon position has the greatest impact on the physico-chemical properties of the encoded amino acid (Knight et al. 1999; Biro et al. 2003). In this study, $84.1 \%$ of the created codons had a central pyrimidine. Codons with central pyrimidines avoid any charged amino acids and all the stop codons. Both constraints could minimize the effect of insertional editing on the resulting protein. The question remains whether the purine-pyrimidine bias is a consequence of the DNA polymerase, a preferred target for the RNA polymerase, or due to selection at the protein level. It should be noted that the purine-pyrimidine editing bias is also seen in non-protein-coding genes, suggesting that it derives from an intrinsic property of the editing mechanism.

Twice as many AU dinucleotides as $\mathrm{GU}$ dinucleotides occurred upstream of $\mathrm{C}$ insertions in the protein-coding genes of P. polycephalum (Gott et al. 2005) and the small subunit ribosomal RNA (SSU rRNA) of a variety of myxomycetes (Krishnan et al. 2007). In this study, three times more upstream AU dinucleotides than GU dinucleotides were observed (104 and 34, respectively). This may be a consequence of an AT-rich mitochondrial genome rather than a preferred signal. The reason for the greater than expected number of $\mathrm{C}$ insertions following UA dinucleotides is unclear; however, this may also be a consequence of the AT-rich mitochondrial genome.

Regardless of the position of the inserted $\mathrm{C}$ nucleotide, this study revealed a significant bias toward $\mathrm{C}$ insertions 
creating hydrophobic amino acid codons. All other types of created codons were under-represented compared with the overall codon usage. The proteins in this study were comprised of $53 \%$ hydrophobic amino acids, while $68 \%$ of the codons created by $\mathrm{C}$ insertions were hydrophobic. A preference toward the creation of hydrophobic amino acid codons may minimize the effect of insertional editing at the protein level. A study of RNA editing sites in plant mitochondria found preferential editing of sites affecting the core protein structure; in addition, editing increased the number of hydrophobic amino acids (Yura and Go 2008).

\section{$\mathrm{U}$ and dinucleotide insertions are either conserved between $D$. iridis and $P$. polycephalum, or conserve the coding sequence}

Only nine $\mathrm{U}$ insertions were observed in four of the 10 genes analyzed in this study. Seven of the nine insertions were conserved editing events between $D$. iridis and $P$. polycephalum. The two $\mathrm{U}$ insertions unique to $D$. iridis matched the encoded sequence of the corresponding $P$. polycephalum mRNA, conserving the codon. Assuming that $\mathrm{U}$ insertions are ancestral to $\mathrm{C}$ insertions as proposed by Horton and Landweber (2000), these few U insertions may be remnants of a time when $\mathrm{U}$ insertions predominated, or insertional editing events may have proliferated after the switch to preferentially inserting $\mathrm{C}$ nucleotides. Though the number of events is small, the greater conservation of $U$ editing events (or conservation of sequence at these sites) may represent the retention of $U$ insertion events that restored the reading frame as well as specifying functionally important amino acids. Otherwise, the conservation of sequence would not be expected at unique editing sites.

The context of the $\mathrm{U}$ insertion sites was examined to look for similarities with $\mathrm{C}$ insertions sites. Six $\mathrm{U}$ insertion events were ambiguous due to an adjacent $U$ nucleotide. Wang et al. (1999) also noted a high proportion of $U$ insertions adjacent to genomically encoded $U$ nucleotides (9/10 U insertions in P. polycephalum and Didymium nigripes). Of the three unambiguous $\mathrm{U}$ insertions, only one fit the pattern of a purine-pyrimidine-third codon position $U$ insertion. However, five of the ambiguous insertions could follow the purine-pyrimidine pattern, and three of these could represent third codon position $U$ insertions. If more $\mathrm{U}$ insertions are discovered it may be possible to determine if the $\mathrm{C}$ insertion bias, for following a purine-pyrimidine dinucleotides and inserting at the third codon positon, evolved before or after $\mathrm{C}$ insertions came to predominate.

There was complete conservation of dinucleotide insertion events between $D$. iridis and $P$. polycephalum in the 10 genes examined. A similar increased level of dinucleotide conservation was observed in the SSU rRNA editing events in a diverse group of myxomycetes when compared with other kinds of editing events (Krishnan et al. 2007). If the reversion of a single nucleotide deletion is a rare event, the reversion of a dinucleotide deletion event should be very rare. In addition, in vitro and in vivo studies in $P$. polycephalum suggest that additional factors may assist in these dinucleotide editing events (Byrne and Gott 2004), which may add to their evolutionary stability.

\section{C-to-U changes are distinct from insertional editing events}

In P. polycephalum, C-to-U changes are thought to occur post-transcriptionally (Visomirski-Robic and Gott 1995). Seven C-to-U changes have been observed, three in D. iridis (two in the coxl gene and one in the cox 2 gene) and four in the cox 1 gene of $P$. polycephalum. These changes all occur in the first or second codon position. In both $D$. iridis and $P$. polycephalum, each change significantly changes the properties of the amino acid encoded, and the change results in coding for amino acids conserved in homologous protein sequences. This mode of RNA editing has been likened to the type of RNA editing in plant organelles (Horton and Landweber 2002), where base changes also occur preferentially in the first and second codon positions and result in a conserved protein sequence.

\section{Multispecies comparison of cox 1 editing suggests that all editing events are under selection at the protein level}

A phylogenetic study of RNA editing in five myxomycete coxl genes (Horton and Landweber 2000) indicated a diversification of editing mechanisms with independent evolutionary histories. When we compared six coxl genes at homologous edited and encoded sites, the resulting mRNAs had a conserved nucleotide sequence or conserved the properties of the resulting amino acid (in all but one case). Dinucleotide insertion editing events were conserved, while $\mathrm{C}$-to- $\mathrm{U}$ changes were the least conserved editing events. However, C-to- $\mathrm{U}$ base changes always resulted in the encoding of conserved amino acids. Single nucleotide insertion editing events showed intermediate levels of conservation.

\section{CONCLUSIONS}

The multiple and distinct types of mRNA editing events in myxomycetes seems chaotic at first glance. However, each type of editing event usually leads to the preservation of a conserved protein product. C-to- $\mathrm{U}$ base changes preferentially occurred at codon positions that changed the properties of the encoded amino acid and resulted in a conserved amino acid residue. Single nucleotide insertions restore the reading frame and minimize the effect at the protein level by preferentially inserting into silent positions. We noted 
TABLE 7. RT-PCR and PCR reamplication primers and reaction annealing temperatures

\begin{tabular}{|c|c|c|c|c|}
\hline Gene & Segment & Forward primer & Reverse primer & Tanneal $^{\mathrm{a}}$ \\
\hline \multirow[t]{10}{*}{ atp1 } & Diatp1.0 & 5'-ATAAACAAAAAGCGCAAGGC-3' & 5'-GACCATCGACAACTCTACCA-3' & $48^{\circ} \mathrm{C}$ \\
\hline & PCR Re-Amp & 5'-ATAAACAAAAAGCGCAAGGC-3' & 5'-GACCATCGACAACTCTACCA-3' & $48^{\circ} \mathrm{C}$ \\
\hline & Diatp1.1 & 5'-GAAAAAGATCAAGTGGTTGTATTGT-3' & 5'-GAAATATTCGCAATGGCACA-3' & $49^{\circ} \mathrm{C}$ \\
\hline & PCR Re-Amp & 5'-GAAAAAGATCAAGTGGTTGTATTGT-3' & 5'-GAAATATTCGCAATGGCACA-3' & $50^{\circ} \mathrm{C}$ \\
\hline & Diatp1.2 & 5'GCTACTGCTGCTCAAAGTGC-3' & 5'-GCAGCAGCTAAAATAATATAACTTG-3' & $49^{\circ} \mathrm{C}$ \\
\hline & PCR Re-Amp & 5'GCTACTGCTGCTCAAAGTGC-3' & 5'-GCAGCAGCTAAAATAATATAACTTG-3' & $50^{\circ} \mathrm{C}$ \\
\hline & Diatp1.3 & 5'-TTACTGATGGCCAAATTTTC-3' & 5'-ACCTTGAGAAATAAAGTTGA-3' & $45^{\circ} \mathrm{C}$ \\
\hline & PCR Re-Amp & 5'-ACCAGCTGTCAATGTCGGTA-3' & 5'-ACCTTGAGAAATAAAGTTGA-3' & $45^{\circ} \mathrm{C}$ \\
\hline & Diatp1.4 & 5'-GCTATCTTGACTTATGAAGC-3' & 5'-GCGTTCGACTAGCATGTATC-3' & $47^{\circ} \mathrm{C}$ \\
\hline & PCR Re-Amp & No reamplification needed & & \\
\hline \multirow[t]{6}{*}{ atp6 } & Diatp6(2).1 & 5'-TCAGTGCTGCTTTAGATACTAGTGTG-3' & 5'-GACCAGCTTGTTCTGCAACT-3' & $49^{\circ} \mathrm{C}$ \\
\hline & PCR Re-Amp & 5'-TCAGTGCTGCTTTAGATACTAGTGTG-3' & 5'-GACCAGCTTGTTCTGCAACT-3' & $51^{\circ} \mathrm{C}$ \\
\hline & Diatp6.1 & 5'-CCTTGGTTTTAATAGTTTCT-3' & 5'-AGCTCCAGCTAAATATGAAG-3' & $44^{\circ} \mathrm{C}$ \\
\hline & PCR Re-Amp & 5'-TATTAACAATAGTTATTAGC-3' & 5'-AGCTCCAGCTAAATATGAAG-3' & $39^{\circ} \mathrm{C}$ \\
\hline & Diatp6.2 & 5'-ATTGCTTGGATTATGTTGGT-3' & 5'-TTAACGTATAACAATATATG-3' & $39^{\circ} \mathrm{C}$ \\
\hline & PCR Re-Amp & 5'-ATTGCTTGGATTATGTTGGT-3' & 5'-TTAATGTGCAATAAGTGAGT-3' & $45^{\circ} \mathrm{C}$ \\
\hline \multirow[t]{2}{*}{ atp8 } & Diatp8.1 & 5'-TTAAATTAGTATAAAAAAATAAAGT-3' & 5'-GTGCAAAAATGACGAATAATGATGA-3' & $41^{\circ} \mathrm{C}$ \\
\hline & PCR Re-Amp & 5' -TTAAATTAGTATAAAAAAATAAAGT-3' & 5'-GTGCAAAAATGACGAATAATGATGA-3' & $41^{\circ} \mathrm{C}$ \\
\hline \multirow[t]{2}{*}{ atp9 } & Diatp9.1 & 5'-CGCCCGAATTATTTAAGTAATCT-3' & 5'-CATCATTAAGGCTAATAATCCACAG-3' & $45^{\circ} \mathrm{C}$ \\
\hline & & No reamplification needed & & \\
\hline \multirow[t]{10}{*}{$\operatorname{cox} 1$} & Dicox1.1 & 5'-GAATAGAATATAAAATAAAAAATATAG-3' & 5'-CAGTCCATCCAGTACCAGCA-3' & $40^{\circ} \mathrm{C}$ \\
\hline & PCR Re-Amp & 5'-GAATAGAATATAAAATAAAAAATATAG-3' & 5'-CAGTCCATCCAGTACCAGCA-3' & $40^{\circ} \mathrm{C}$ \\
\hline & Dicox1.2 & 5'-CACGTTTAAAAATATTAGCTATGGT-3' & 5'-CTAAATACCAATGGATAACATAGCA-3' & $48^{\circ} \mathrm{C}$ \\
\hline & PCR Re-Amp & 5'-CACGTTTAAAAATATTAGCTATGGT-3' & 5'-CTAAATACCAATGGATAACATAGCA-3' & $48^{\circ} \mathrm{C}$ \\
\hline & Dicox1.3 & 5'-TATAATTCAAACTATGCCAATAAAG-3' & 5'-AAATCACGACGACATATGGT-3' & $46^{\circ} \mathrm{C}$ \\
\hline & PCR Re-Amp & 5'-TATAATTCAAACTATGCCAATAAAG-3' & 5'-AAATCACGACGACATATGGT-3' & $47^{\circ} \mathrm{C}$ \\
\hline & Dicox1.4 & 5'GGTGGTCTTAGTGGAGTTGT-3' & 5'-AATTAAGTAATATAAGAACCATAACTACTA-3' & $46^{\circ} \mathrm{C}$ \\
\hline & PCR Re-Amp & 5'-GGTGGTCTTAGTGGAGTTGT-3' & 5'-AATTAAGTAATATAAGAACCATAACTACTA-3' & $48^{\circ} \mathrm{C}$ \\
\hline & Dicox 1.5 & 5'-AGCTGGTATGCCACGACGTA-3' & 5'-ATTTGAGATTAATTTTTGTGC-3' & $43^{\circ} \mathrm{C}$ \\
\hline & PCR Re-Amp & 5'-AGCTGGTATGCCACGACGTA-3' & 5'-ATTTGAGATTAATTTTTGTGC-3' & $43^{\circ} \mathrm{C}$ \\
\hline \multirow[t]{4}{*}{$\cos 2$} & Dicox2.2 & 5'-ATGTTTTGTTTTTTAGGGTT-3' & 5'-ATAAACGAGTTCACCTTCAA-3' & $41^{\circ} \mathrm{C}$ \\
\hline & PCR Re-Amp & No reamplification needed & & \\
\hline & Dicox2.3 & 5'-TAATTAGGTCTTGAATGGGA-3' & 5'-TCACATAAAATTTAGAGTTAAAAGT-3' & $41^{\circ} \mathrm{C}$ \\
\hline & PCR Re-Amp & No reamplification needed & & \\
\hline \multirow[t]{6}{*}{ cytb } & Dicytb.1 & 5'-AATTAAGAATTTTTTTTATCCTAGAA-3' & 5'-ATGCAACGTGCAATAAGACT-3' & $41^{\circ} \mathrm{C}$ \\
\hline & PCR Re-Amp & 5'-AATTAAGAATTTTTTTTATCCTAGAA-3' & 5'-ATGCAACGTGCAATAAGACT-3' & $44^{\circ} \mathrm{C}$ \\
\hline & Dicytb.2 & 5'-AGCCTCAACAGTACССТTCT-3' & 5'-AATACGTAGTCAAACGCCCAA-3' & $52^{\circ} \mathrm{C}$ \\
\hline & PCR Re-Amp & 5'-TTACCTTTTTGTCATCTTAGC-3' & 5'-GTTCTTCTAATGGTGATTGTC-3' & $46^{\circ} \mathrm{C}$ \\
\hline & Dicytb.3 & 5'-TTTTCTCCCGTTCTATGCCA-3' ${ }^{\prime c}$ & 5'-AATAGTTATCTTTTTTTTTTG-3'b & $50^{\circ} \mathrm{C}$ \\
\hline & PCR Re-Amp & 5'-TTTTTCTCCCGTTCTATGCCA-3' & 5'-AATAGTTATCTTTTTTTTTTG-3' & $38^{\circ} \mathrm{C}$ \\
\hline \multirow[t]{2}{*}{ nadL } & Dinad4L.1 & 5'-ATAGCTGACTCTTACATTTCTAACT-3' & 5'-GTTCAAAAGGATTAAAGAGCATCTG-3' & $45^{\circ} \mathrm{C}$ \\
\hline & PCR Re-Amp & 5'-ATAGCTGACTCTTACATTTCTAACT-3' & 5'-GTTCAAAAGGATTAAAGAGCATCTG-3' & $45^{\circ} \mathrm{C}$ \\
\hline nad6 & Dinad6.1 & $\begin{array}{l}\text { 5'-ATGTATTTTTTTTTTAAGAATTTTTTATTACT-3' } \\
\text { No reamplification needed }\end{array}$ & 5'-GGAGATGGATTACTAAATGAAATGA-3' & $45^{\circ} \mathrm{C}$ \\
\hline \multirow[t]{6}{*}{ nad7 } & Dinad7.1 & 5'-ACGAGTTTATAGTTCAAAACACGTA-3' & 5'-ACGATCTTTAAATATACGATTCTCA-3' & $49^{\circ} \mathrm{C}$ \\
\hline & PCR Re-Amp & 5'-ACGAGTTTATAGTTCAAAACACGTA-3' & 5'-ACGATCTTTAAATATACGATTCTCA-3' & $0^{\circ} \mathrm{C}$ \\
\hline & Dinad7.2 & 5'-AGGTGTAGCTTTCGATTTGC-3' & 5'-AAGTACCATAATAGCTACACATCAG-3' & $48^{\circ} \mathrm{C}$ \\
\hline & PCR Re-Amp & 5'-TTACСTTTTTCAAGAAAATTAACTG-3' & 5'-AAGTACCATAATAGCTACACATCAG-3' & $47^{\circ} \mathrm{C}$ \\
\hline & Dinad7.3 & 5'-GTAATGCCAGAAGGTACTGT-3' & 5'-TGCGTTTTTTTTTTCCTTTAG-3' & $42^{\circ} \mathrm{C}$ \\
\hline & PCR Re-Amp & 5'-CGTTGTCATATACGTGCTCC-3' & 5'-AAAAAAGCATACGACCCCAA-3' & $48^{\circ} \mathrm{C}$ \\
\hline
\end{tabular}

${ }^{a}$ Annealing temperature for the reaction.

${ }^{\mathrm{b}}$ First strand synthesis; $10 \mathrm{~min}$ at $37^{\circ} \mathrm{C}, 20 \mathrm{~min}$ at $42^{\circ} \mathrm{C}$, and $10 \mathrm{~min}$ at $45^{\circ} \mathrm{C}$.

${ }^{\mathrm{C}}$ No additional reverse primer was added to do asymmetric PCR. 
a preference for creating hydrophobic amino acid codons by single-base insertions. Hydrophobic amino acid codons are the most abundant ( 25 codons) and, in our data set, they are the most frequently used codons (53.2\%). This suggests that editing mechanisms that preferentially create hydrophobic amino acids might be the safest, on average. The bias toward third codon position base insertions following purine-pyrimidine dinucleotides helps enrich for hydrophobic amino acid codons, since codons with central pyrimidines are mainly hydrophobic. In addition, codons with central pyrimidines avoid charged amino acids and stop codons. The question remains as to whether this pattern was driven by a deletion-prone DNA polymerase or an RNA polymerase that could add untemplated nucleotides, or both. However, selection at the protein level appears to be strong for all types of mRNA editing events, based on our comparisons.

\section{MATERIALS AND METHODS}

\section{Isolation of DNA and RNA}

The haploid Pan2-16 strain of D. iridis (Clark et al. 1991) was used as the source material for DNA and RNA isolations. The cells were cultivated axenically on peptone-glucose-yeast medium supplemented with heat-killed Escherichia coli (Silliker et al. 1988). Mitochondrial DNA isolation and cloning was described previously (Silliker et al. 2002). RNA was isolated with the TRIzol Reagent (Invitrogen). One unit of amplification grade DNase I (Sigma) was used to treat $1 \mu \mathrm{g}$ of RNA; the digestion was at $22^{\circ} \mathrm{C}$ for $15 \mathrm{~min}$ in the buffer provided.

\section{RT-PCR, cloning, and sequencing}

RT-PCR was accomplished using the SuperScript III one-step RTPCR kit with Platinum Taq DNA polymerase (Invitrogen); the reactions contained $\sim 500 \mathrm{ng}$ of total RNA and the primers were at a final concentration of $0.2 \mu \mathrm{M}$. In most cases the products needed to be reamplified with the same or nested primers; $50 \mu \mathrm{L}$ of PCR reactions contained $4 \mu \mathrm{L}$ of the RT-PCR reaction, primer at $0.25 \mu \mathrm{M}$, and $\mathrm{Taq}$ polymerase master mix (MidSci) diluted to the $1 \mathrm{x}$ concentration. The primers and reaction temperatures for each gene segment are listed in Table 7. Amplification products were cloned into the pCR4-TOPO cloning vector (Invitrogen). At least three independent clones were sequenced on both strands for each gene segment. DNA sequencing used the ABI Big Dye Terminator v3.1 reagent and bases were called on an ABI 310 sequencer (Applied Biosystems). The sequences are available from GenBank under the following accession numbers, where $-\mathrm{D}$ is the genomic sequence and $-\mathrm{R}$ is the edited sequence: (atp1-D) GU182118, (atp1-R) GU182119, (atp 6-D) GU182120, (atp6-R) GU182121, (atp8-D) GU182122, (atp8-R) GU182123, (atp9-D) GU182124, (atp9-R) GU182125, (cox1-D) GU182126, (cox1-R) GU182127, (cox2-D) GU182128, (cox2-R) GU182129, (cytb-D) GU182130, (cytb-R) GU182131, (nad4L-D) GU182132, (nad4L-R) GU182133, (nad6-D) GU182134, (nad6-R) GU182135, (nad7-D) GU182136, and (nad7-R) GU182137.

\section{Sequence Analysis}

Sequences were trimmed manually and the gene segments were overlapped using Sequencher 4.9 (Gene Codes). The BLAST suite was used for similarity searches (http://blast.ncbi.nlm.nih.gov/ Blast.cgi) and Clustal W was used for sequence alignments (Larkin et al. 2007).

\section{SUPPLEMENTAL MATERIAL}

Supplemental material can be found at http://www.rnajournal.org.

\section{ACKNOWLEDGMENTS}

We thank Dr. Ralf Bundschuh of The Ohio State University for his PIE analysis of the atp 8 and nad4L genes at the start of this project. This work was supported by grants from the DePaul University Research Council and the DePaul University College of Liberal Arts and Sciences Faculty Development Fund to M.E.S. M.J.D. received support from the DePaul University College of Liberal Arts and Sciences Undergraduate Research Assistant Program and Undergraduate Research and Development Summer Grant Program. We are also grateful for the helpful and insightful comments of the anonymous reviewers.

Received November 6, 2009; accepted December 22, 2009.

\section{REFERENCES}

Antes T, Costandy H, Mahendran R, Spottswood M, Miller D. 1998. Insertional editing of mitochondrial tRNAs of Physarum polycephalum and Didymium nigripes. Moll Cell Biol 18: 7521-7527.

Baldauf SL, Roger AJ, Wenk-Siefert I, Doolittle WF. 2000. A kingdomlevel phylogeny of eukaryotes based on combined protein data. Science 290: 972-977.

Beargie C, Liu T, Corriveau M, Lee HY, Gott J, Bundschuh R. 2008. Genome annotation in the presence of insertional RNA editing. Bioinformatics 24: 2571-2578.

Benne R, Van Den Burg J, Brakenhoff JPJ, Sloof P, Van Boom JH, Tromp MC. 1986. Major transcript of the frameshifted coxll gene from trypanosome mitochondria contains four nucleotides that are not encoded in the DNA. Cell 46: 819-826.

Biro JC, Benyo B, Sansom C, Szlavecz A, Fordos G, Micsik T, Benyo Z. 2003. A common periodic table of codons and amino acids. Biochem Biophys Res Commun 306: 408-415.

Bundschuh R. 2004. Computational prediction of RNA editing sites. Bioinformatics 20: 3214-3220.

Byrne EM, Gott JM. 2004. Unexpectedly complex editing patterns at dinucleotide insertion sites in Physarum mitochondria. Mol Cell Biol 24: 7821-7828.

Clark J, Collins ONR, Tang H-C. 1991. Didymium iridis mating systems: Partial compatibility between mating series. Mycologia 83: 210-213.

Covello PS, Gray MW. 1993. On the evolution of RNA editing. Trends Genet 9: 265-268.

Fiore-Donno AM, Berney CD, Pawlowski J, Baldauf SL. 2005. Higherorder phylogeny of plasmodial slime molds (Myxogastria) based on elongation factor 1-A and small subunit rRNA gene sequences. J Eukaryot Microbiol 52: 201-210.

Gott JM. 2003. Expanding genome capacity via RNA editing. C R Biol 326: 901-908.

Gott JM, Rhee AC. 2008. Insertion/deletion editing in Physarum polycephalum. In RNA editing, pp. 85-104.

Gott JM, Visomirski LM, Hunter JL. 1993. Substitutional and insertional RNA editing of the cytochrome $\mathrm{c}$ oxidase subunit 1 
mRNA of Physarum polycephalum. J Biol Chem 268: 2548325486.

Gott JM, Parimi N, Bundschuh R. 2005. Discovery of new genes and deletion editing in Physarum mitochondria enabled by a novel algorithm for finding edited mRNAs. Nucleic Acids Res 33: $5063-$ 5072.

Gray M. 2003. Diversity and evolution of mitochondrial RNA editing systems. Informa Healthcare 55: 227-233.

Heidel AJ, Glockner G. 2008. Mitochondrial genome evolution in the social amoebae. Mol Biol Evol 25: 1440-1450.

Horton TL, Landweber LF. 2000. Evolution of four types of RNA editing in myxomycetes. RNA 6: 1339-1346.

Horton TL, Landweber LF. 2002. Rewriting the information in DNA: RNA editing in kinetoplastids and myxomycetes. Curr Opin Microbiol 5: 620-626.

Johansen S, Johansen T, Haugli F. 1992. Extrachromosomal ribosomal DNA of Didymium iridis: Sequence analysis of the large subunit ribosomal RNA gene and sub-telomeric region. Curr Genet 22: 305-312.

Knight RD, Freeland SJ, Landweber LF. 1999. Selection, history, and chemistry: The three faces of the genetic code. Trends Biochem Sci 24: 241-247.

Krishnan U, Barsamian A, Miller DL. 2007. Evolution of RNA editing sites in the mitochondrial small subunit rRNA of the Myxomycota. Methods Enzymol 424: 197-220.

Larkin MA, Blackshields G, Brown NP, Chenna R, McGettigan PA, McWilliam H, Valentin F, Wallace IM, Wilm A, Lopez R, et al. 2007. Clustal W and Clustal X version 2.0. Bioinformatics 23: 2947-2948.

Liu T, Bundschuh R. 2005. Model for codon position bias in RNA editing. Phys Rev Lett 95: 4. doi: 10.1103/PhysRevLett.95.088101.

Mahendran R, Spottswood MR, Miller DL. 1991. RNA editing by cytidine insertion in mitochondria of Physarum polycephalum. Nature 349: 434-438.
Mahendran R, Spottswood MS, Ghate A, Ling ML, Jeng K, Miller DL. 1994. Editing of the mitochondrial small subunit rRNA in Physarum polycephalum. EMBO J 13: 232-240.

Miller ML, Miller DL. 2008. Non-DNA-templated addition of nucleotides to the $3^{\prime}$ end of RNAs by the mitochondrial RNA polymerase of Physarum polycephalum. Mol Cell Biol 28: 57955802.

Miller D, Mahendran R, Spottswood M, Costandy H, Wang S, Ling M-l, Yang N. 1993. Insertional editing in mitochondria of Physarum. Semin Cell Biol 4: 261-266.

Miller M, Antes T, Qian F, Miller D. 2006. Identification of a putative mitochondrial RNA polymerase from Physarum polycephalum: Characterization, expression, purification, and transcription in vitro. Curr Genet 49: 259-271.

Rhee AC, Somerlot BH, Parimi N, Gott JM. 2009. Distinct roles for sequences upstream of and downstream from Physarum editing sites. RNA 15: 1753-1765.

Silliker ME, Gong T, Collins OR. 1988. Spore-to-spore cultivation of Didymium iridis on heat-killed bacteria. Mycologia 80: 151156.

Silliker ME, Liles JL, Monroe JA. 2002. Patterns of mitochondrial inheritance in the myxogastrid Didymium iridis. Mycologia 94: 939-946.

Speijer D. 2008. Evolution aspects of RNA editing. Nucleic Acids and Molecular Biology 20: 199-227.

Visomirski-Robic LM, Gott JM. 1995. Accurate and efficient insertional RNA editing in isolated Physarum mitochondria. RNA 1: 681-691.

Wang SSQ, Mahendran R, Miller DL. 1999. Editing of cytochrome b mRNA in Physarum mitochondria. J Biol Chem 274: 2725-2731.

Yura K, Go M. 2008. Correlation between amino acid residues converted by RNA editing and functional residues in protein three-dimensional structures in plant organelles. BMC Plant Biol 8: 79. doi: 10.118/1471-2209-8-79. 